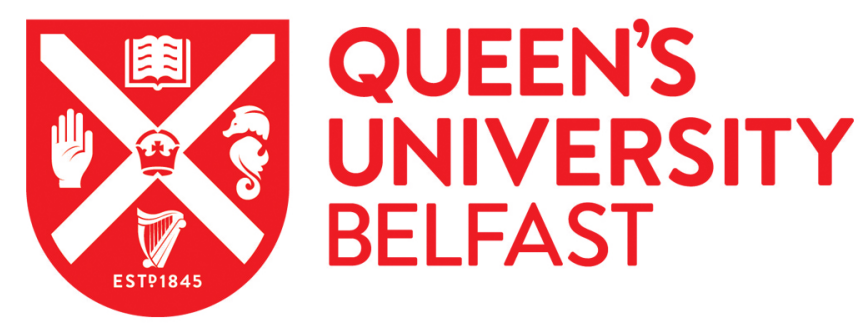

\title{
Alterations in retinal arteriolar microvascular structure associates with higher treatment burden in patients with diabetic macular edema: results from a 12-month prospective clinical trial
}

Blindbæk, S. L., Peto, T., \& Grauslund, J. (2019). Alterations in retinal arteriolar microvascular structure associates with higher treatment burden in patients with diabetic macular edema: results from a 12-month prospective clinical trial. Acta Ophthalmologica. https://doi.org/10.1111/aos.14278

\section{Published in:}

Acta Ophthalmologica

\section{Document Version:}

Peer reviewed version

Queen's University Belfast - Research Portal:

Link to publication record in Queen's University Belfast Research Portal

\author{
Publisher rights \\ (c) 2019 Acta Ophthalmologica Scandinavica Foundation. Published by John Wiley \& Sons Ltd. This work is made available online in \\ accordance with the publisher's policies. Please refer to any applicable terms of use of the publisher.
}

\section{General rights}

Copyright for the publications made accessible via the Queen's University Belfast Research Portal is retained by the author(s) and / or other copyright owners and it is a condition of accessing these publications that users recognise and abide by the legal requirements associated with these rights.

Take down policy

The Research Portal is Queen's institutional repository that provides access to Queen's research output. Every effort has been made to ensure that content in the Research Portal does not infringe any person's rights, or applicable UK laws. If you discover content in the Research Portal that you believe breaches copyright or violates any law, please contact openaccess@qub.ac.uk. 
Title:

Alterations in retinal arteriolar microvascular structure associates with higher treatment burden in patients with diabetic macular edema: results from a 12-month prospective clinical trial.

Søren L Blindbæk, MD ${ }^{1,2,3}$, Tunde Peto, PhD², , Jakob Grauslund, DMSci ${ }^{1,2,5}$

${ }^{1}$ Department of Ophthalmology, Odense University Hospital, Odense, Denmark

${ }^{2}$ Department of Clinical Research, University of Southern Denmark, Odense, Denmark

${ }^{3}$ OPEN, Open Patient data Explorative Network, Odense University Hospital, Odense, Denmark

${ }^{4}$ Centre for Public Health, Queen's University Belfast, Belfast, United Kingdom.

${ }^{5}$ Steno Diabetes Center Odense, Odense, Denmark

\section{Word count}

Abstract: 250 (excluding headings)

Manuscript: 3703 (excluding headings, tables, figures and legend

Corresponding Author:

Søren Leer Blindbæk

Department of Ophthalmology, Odense University Hospital, Odense, Denmark

Sdr. Boulevard 29, Odense C - DK-5000

Phone: +4521794056

E-mail: Soeren.leer.blindbaek@rsyd.dk

Fax: +4566123468 


\section{ABSTRACT}

Purpose: This study was based on data from a 12-months prospective clinical trial and aimed to examine changes in retinal microvascular structure in eyes treated with intravitreal aflibercept in combination with focal/grid laser photocoagulation for diabetic macular edema (DME).

Methods: We included 32 treatment naïve eyes of 22 patients with center involving DME. The treatment algorithm comprised a loading phase of three monthly injections of aflibercept and focal/grid laser photocoagulation (baseline (BL)-month $3(\mathrm{M} 3)$ ) followed by a pro re nata (PRN) aflibercept phase until month 12 (M12). Eyes were divided in groups with and without need for PRN treatment after loading. Parameters of retinal microvascular structure were measured in $45^{\circ}$ optic disc centered fundus images at BL, M3 and M12 using a semi-automated software (VAMPIRE-Web, Vessel Assessment and Measurement Platform for Images of the Retina, Universities of Dundee and Edinburgh, UK).

Results: A significant decrease in retinal arteriolar calibre was demonstrated at both M3 (-11.2 $\mu \mathrm{m}$, $\mathrm{p}=0.005)$ and $\mathrm{M} 12(-11.5 \mu \mathrm{m}, \mathrm{p}=0.04)$ as compared to baseline in eyes that needed PRN treatment during follow up. In contrast, arteriolar calibre remained unchanged in eyes without need for PRN treatment (M3: $-1.6 \mu \mathrm{m}, \mathrm{p}=0.79$ and $\mathrm{M} 12:-7.0 \mu \mathrm{m}, \mathrm{p}=0.22)$. For retinal venules, vessel caliber decreased both in eyes with and without need for PRN therapy at M3 $(-9.5 \mu \mathrm{m}, \mathrm{p}=0.01$ and $-11.6 \mu \mathrm{m}, \mathrm{p}=0.01)$ as well as at M12 $(-15.6$ $\mu \mathrm{m}, \mathrm{p}=0.001$ and $-11.0 \mu \mathrm{m}, \mathrm{p}=0.04)$.

Conclusion: Early changes in retinal arteriolar caliber are associated with an increased treatment burden during the first year of DME-treatment.

Keywords: diabetic macular edema, anti-VEGF, retinal imaging, prospective clinical trial 


\section{INTRODUCTION}

The estimated number of patients with diabetes globally reached 425 million in 2017 (Cho et al. 2017). Diabetic retinopathy (DR) is the most common complication of diabetes and is almost universal in patients with long duration of the disease (Grauslund et al. 2009; Cheung et al. 2010). End stage DR comprises proliferative DR (PDR) and diabetic macula edema (DME) of which DME is the leading cause of preventable vision loss in the working age population of the developed countries and can occur at any stage of DR (Klein et al. 2010; Antonetti et al. 2012; Tan et al. 2017).

Vascular endothelial growth factor (VEGF) is a key mediator in the development and progression of diabetic macular edema (DME) and, hence, VEGF is currently a primary target in DMEtreatment (Aiello et al. 1994). The release of VEGF is largely driven by retinal ischemia and tissue hypoxia as a consequence of hyperglycemic damage to the retinal microvascular structure (Cogan \& Kuwabara 1963; Stitt et al. 2016). The upregulation of VEGF during disease progression ultimately causes vasodilation and increased permeability of the vessel wall leading to hyper-perfusion, increased hydrostatic pressure and ultimately fluid leakage and macular edema (Senger et al. 1986; Aiello et al. 1994; Ferrara 1999).

Changes in retinal microvascular structure have been associated with several systemic diseases as well as the development and progression of diabetic retinopathy (DR) in persons with diabetes in large population based studies. Thus, wider venular caliber have consistently been associated with more severe stages of DR while narrower arteriolar caliber as well as lower fractal dimension is associated with an increased risk of progression to vision threatening DR (Klein et al. 2004; Kifley et al. 2008; Klein et al. 2012; Broe et al. 2014).

Due to the association with both the severity and the progression of the disease, changes in retinal microvascular structure during treatment have been a subject of interest in several retinal vascular diseases. Thus, the diameter of macular vessels has been demonstrated to decrease following focal/grid laser treatment in patients with DME (Lundberg et al. 2013). Similar results have been demonstrated with inhibitors of VEGF (anti-VEGF) in the treatment of neovascular age related macular degeneration (nAMD) while results in regards of anti-VEGF treatment of DME are limited (Tatlipinar et al. 2012; Wickremasinghe et al. 2012; Consigli et al. 2018; Min et al. 2018; Tetikoglu et al. 2018).

Furthermore, only one study has addressed the association between retinal microvascular structure prior to treatment and treatment outcome in patients with DME (Moradi et al. 2014). They demonstrated that wider venular caliber at baseline was associated with better visual outcome after treatment with intravitreal ranibizumab. However, only vessel calibers were examined and without information on changes during treatment.

We recently demonstrated that during the first year of DME-treatment, approximately $40 \%$ of eyes did not need additional intravitreal therapy after combination therapy with three monthly injections of intravitreal aflibercept and focal/grid laser photocoagulation (Blindbaek et al. 2019).

Hence, in this ancillary analysis based on data from a 12-month randomized clinical trial we aimed to evaluate baseline parameters of retinal microvascular structure as predictors of need for additional therapy after combination treatment for DME. We hypothesize that parameters of retinal microvascular structure prior to treatment differ between eyes with different need for therapy. Furthermore, we wanted to examine whether changes in retinal microvascular structures can be used as a postoperative marker of need for therapy. 


\section{METHODS}

107

This study was based on data from a previously reported 12-month randomized clinical trial and included 32 treatment naïve eyes of 22 patients with center involving DME. Patients were recruited at referral to Odense University Hospital, Denmark, between 1 October 2015 and 31 December 2017.

Inclusion criteria were center involving DME, age 18-99 years, best corrected visual acuity (BCVA) 35-80 Early Treatment Diabetic Retinopathy Study (ETDRS) letters and central retinal thickness (CRT) >300 $\mu \mathrm{m}$. Patients who were pregnant, had active proliferative diabetic retinopathy, a history of panretinal photocoagulation, had received any previous DME-treatment or had been subjected to intraocular surgery within four months prior to inclusion were excluded.

At baseline (BL), all patients provided a full medical history and underwent ophthalmic evaluation including BCVA using ETDRS charts (Precision Vison, Illinois, USA) at a starting distance of four meters followed by slit lamp and fundus bio microscopy in mydriasis with tropicamide $10 \mathrm{mg} / \mathrm{mL}$ and phenylephrine $10 \%$, fundus photography and optical coherence tomography (OCT) (3D OCT-2000 Spectral domain OCT, Topcon, Tokyo, Japan) (twelve-line radial scan) and 50 degrees macula-centered fundus fluorescein angiography (TRC-50DX fundus camera, Topcon, Tokyo, Japan).

Furthermore, BL examination included measurement of brachial arterial blood pressure (Omron $705 \mathrm{CP}$, Hoofdrop, The Netherlands) and hemoglobin A1c (HbA1c) (Tosoh G8, Alere, Holstebro, Denmark). Mean arterial pressure (MAP) was calculated as $B P_{d}+\left(B P_{s}-B P_{d}\right) / 3$ where $B P_{d}$ is the diastolic blood pressure and $\mathrm{BP}_{\mathrm{s}}$ is the systolic blood pressure and body mass index $(\mathrm{BMI})$ as weight $(\mathrm{kg}) / \mathrm{height}(\mathrm{m})^{2}$.

Patients then entered a loading phase of three monthly injections of $2.0 \mathrm{mg}$ aflibercept followed by focal/grid laser photocoagulation using either Navilas ${ }^{\circledR}$ (OD-OS GmbH, Teltow, Germany) or PASCAL ${ }^{\circledR}$ laser (Optimedica Corp., Santa Clara, CA, USA). After laser until month 12 (M12), patients were scheduled for monthly follow-up and additional aflibercept was administered pro re nata (PRN) if CRT increased with more than $20 \%$ as compared to the lowest measurement or if they experienced a loss in BCVA of more than five ETDRS letters as compared to BL.

As no difference in functional outcome or need for intravitreal therapy was identified between treatment arms of Navilas $^{\circledR}$ and Pascal ${ }^{\circledR}$ laser photocoagulation, data were pooled for further analysis of retinal microvascular structure and grouped according to their need for PRN treatment. For the rest of this paper, eyes without need for PRN treatment after loading and until follow-up at month 12 will be referred to as "PRN $\div$ " and eyes that did need PRN treatment as "PRN+".

\section{Retinal microvascular structure}

Image analysis was performed in $45^{\circ}$ optic disc centered fundus images (3D OCT-2000 Spectral domain OCT, Topcon, Tokyo, Japan) acquired at BL, month three (M3) prior to focal/grid laser photocoagulation and M12 using VAMPIRE-Web (Vessel Assessment and Measurement Platform for Images of the Retina, Universities of Dundee and Edinburgh, UK) (Fig. 1).

All image analyses were performed by a single trained grader (SLB) in accordance with a standard VAMPIRE grading protocol. Image quality was assessed using a binary black and white vessel map demonstrating the software's ability to delineate retinal vessels. A detailed description of the equipment and grading method 
can be found elsewhere (Perez-Rovira et al. 2011; McGrory et al. 2018). In brief, a three-zoned grid is automatically placed around the optic disc by the VAMPIRE software. Zones $A, B$ and $C$ delineate retinal areas between 0-0.5, 0.5-1.0 and 0.5-2.0 disc diameters from the optic disc margin, respectively. Arterioles and venules were automatically labelled and color mapped in red and blue. Misidentified arterioles and venules were secondly manually re-labelled by the grader. Furthermore, if the software erroneously identified artefacts (e.g. hemorrhages and hard exudates) as vessels, if two vessels were detected as one, if a single vessel was registered as two separate vessels or if the delineation of a vessel was unsatisfactory the vessel section was excluded from the analysis (white on color map) (Fig. 1).

The following parameters were measured: vessel calibers are presented as the central retinal artery and vein equivalent, respectively, representing the six largest arterioles and venules coursing through zone B (Knudtson et al. 2003). To ease the interpretation of results, an image conversion factor, based on the assumption of an average disc diameter of $1800 \mu \mathrm{m}$, was used to translate vessel widths from pixels into $\mu \mathrm{m}$. Tortuosity is a mathematical quantification of the curvature of a vessel segment as compared to a reference straight line of the same vessel segment. Vessel density is a simple measure of the total sum of pixels occupied by retinal vessels in a given retinal area and, thus, provides a combined measure of both vessel complexity and vessel width. The fractal dimension characterizes complex, repeating geometrical patterns in different spatial scales. It thus summarizes the branching complexity of the retinal vascular tree in a single non-integer value. Tortuosity, vessel density and fractal dimension are measured in zone $\mathrm{C}$.

\section{Fig. 1}

\section{Statistical analysis}

Statistical calculations were performed using STATA version 15.1 (StataCorp LLC, College Station, TX, USA). Continuous data are presented as mean (with 95\% confidence intervals) and categorical data as percent. Pvalues under 0.05 were considered statistically significant.

Differences between eyes in groups $\mathrm{PRN} \div$ and $\mathrm{PRN}+$, respectively, were tested employing cluster robust standard errors for linear regression models as patients were allowed to participate with both eyes.

\section{Ethics}

This study was carried out in accordance with the Helsinki Declaration and Good Clinical Practice and approved by the Regional Scientific Ethical Committee for Southern Denmark. Informed consent was obtained from all patients for being included in the study. Trial registration: http://www.clinicaltrials.gov (NCT02554747).

\section{RESULTS}

Thirty-nine eyes of 28 patients fulfilled the criteria of inclusion. Two patients were discontinued from the study at month five as eyes were not suitable for laser. One patient died during follow-up of reasons unrelated to the study and one patient dropped out due to hospitalization over other severe complications to diabetes. Finally, three eyes of two patients were excluded as images were deemed ungradable. Thus, 32 eyes of 22 patients were finally included.

Five were women ( 7 eyes) and 17 were men ( 25 eyes). Twenty-one had type 2 diabetes and one had type 1. Mean age and duration of diabetes was 59.5 (57.7-64.3) and 9.2 (4.6-13.7) years, 
respectively, and mean HbA1c was 59.8 (52.2-67.4) mmol/mol. Mean MAP was 101.9 (96.0-107.8) $\mathrm{mmHg}$ and mean BMI was $29.2(26.5-32.0) \mathrm{kg} / \mathrm{m}^{2}$. Mean BCVA was 71.7 (68.2-75.3) ETDRS letters and mean CRT was 387.3 (352.0-422.6) $\mu \mathrm{m}$. Mean arteriolar and venular caliber was 139.9 (133.3-146.5) and 212.8 (206.1219.4) $\mu \mathrm{m}$. Mean tortuosity was $-8.2(-8.8-(-7.7))$ and $-8.4(-8.5-(-8.2))$ for arterioles and venules respectively and likewise mean vessel density was 3961.5 (3514.2-4408.8) and 5532.1 (5108.2-5956.0) pixels. Mean fractal dimension was 1.374 (1.361-1.388).

A more extensive thickening of the central retina was observed in eyes in the PRN+ group as compared to eyes in the PRN $\div$ group $(424.9$ (360.6-489.2) $\mu \mathrm{m}$ vs. $344.6(325.5-363.7) \mu \mathrm{m}, \mathrm{p}=0.03)$ whereas no differences were found between groups in regards of vessel calibers, tortuosity, vessel density, fractal dimension or any other BL parameters (Table 1).

\section{Table 1}

After laser until M12, 46.9\% (15/32) of eyes did not need additional intravitreal therapy and were, thus, categorized as PRN $\div$. According to treatment protocol, the PRN $\div$ group received 3.0 aflibercept injections (loading) between BL and M12 whereas the mean number of injections was 5.2 (4.5-6.0) in the PRN+ group.

From BL to M3 BCVA improved by 8.2 (6.3-10.0) ETDRS letters and at M12 BCVA had improved by 9.2 (7.610.8) ETDRS letters as compared to $B L$ without differences between groups at either time point. Likewise there was a CRT reduction of 104.8 (68.0-141.6) $\mu \mathrm{m}$ between $\mathrm{BL}$ and $\mathrm{M} 3$ and 96.5 (61.4-131.6) $\mu \mathrm{m}$ between $B L$ and M12. Between BL and M3, a numerically greater reduction in CRT was noted in the PRN+ group even though the difference between groups did not reach statistical significance (72.3 (47.6-96.9) $\mu \mathrm{m}$ vs. 133.4 (67.5-169.3) $\mu \mathrm{m}, \mathrm{p}=0.09$ ). Hence, the difference in CRT between the groups demonstrated at BL was no longer present either at M3 or M12 (272.3 (257.1-287.6) $\mu \mathrm{m}$ vs. 291.5 (271.3-311.7) $\mu \mathrm{m}, \mathrm{p}=0.12$ and 273.5 (253.8-293.3) $\mu \mathrm{m}$ vs. 305.9 (269.5-342.4) $\mu \mathrm{m}, \mathrm{p}=0.11)$.

\section{Table 2}

For the entire cohort, retinal arteriolar caliber remained unchanged during the loading phase with intravitreal aflibercept (BL-M3) $(-6.7(-14.0-0.62) \mu \mathrm{m}, \mathrm{p}=0.07)$ whereas a decrease was seen between $\mathrm{BL}$ and M12 (-9.4 (-17.4-(-1.4), $p=0.02)$. For retinal venules, vessel calibers decreased by $10.5(-16.2-(-4.7)) \mu \mathrm{m}$ $(p=0.001)$ during the loading phase and remained constricted at M12 (-13.4 (-20.2-(-6.6)) $\mu \mathrm{m}, \mathrm{p}<0.001$ as compared to baseline).

For the groups separately, a significant decrease in retinal arteriolar caliber was demonstrated after loading (-11.2 (-18.7-(-3.7)) $\mu \mathrm{m}, \mathrm{p}=0.005)$ in eyes that needed additional therapy during follow-up (PRN+). In contrast, retinal arteriolar caliber of eyes in the PRN $\div$ group remained unchanged between $B L$ and M3 $(-1.6$ $(-13.8-10.7) \mu \mathrm{m}, \mathrm{p}=0.79)$. A similar pattern was noted at $\mathrm{M} 12$, at which retinal arteriolar caliber significantly decreased in the PRN+ group $(-11.5(-22.2-(-0.8)) \mu \mathrm{m}, \mathrm{p}=0.04)$ as compared to baseline whereas it remained unchanged in the PRN $\div$ group $(-7.0(-18.6-4.5) \mu \mathrm{m}, \mathrm{p}=0.22)$.

For retinal venules, both groups demonstrated a significant decrease in vessel calibers at both M3 (PRN+: -9.5 (-17.0-(-2.0)) $\mu \mathrm{m}, \mathrm{p}=0.01$ and PRN $\div$ : $-11.6(-20.1-(-3.1)) \mu \mathrm{m}, \mathrm{p}=0.01$ as compared to $\mathrm{BL})$ 
and M12 (PRN+: -11.5 (-22.2-(-0.8)) $\mu \mathrm{m}, \mathrm{p}=0.001$ and PRN $\div:-11.0(-22.1-(-0.19)) \mu \mathrm{m}, \mathrm{p}=0.04$ as compared to $\mathrm{BL})$.

A transient decrease in vessel density of retinal arterioles was noted between $\mathrm{BL}$ and $\mathrm{M} 3$ in the PRN+ group (-367.3 (-720.7-(-13.9)) pixels, $\mathrm{p}=0.04)$. Thus, the decrease was no longer statistical significant at month 12 as compared to baseline. Vessel density remained unchanged at both M3 and M12 as compared to BL for eyes without need for PRN treatment. For the remaining measured parameters of retinal microvascular structure there were no change between $\mathrm{BL}$ and $\mathrm{M} 3$ and M12, respectively (Table 2).

\section{DISCUSSION}

In this explorative study of changes in retinal microvascular parameters during DME-treatment, early changes in retinal arteriolar caliber after loading with intravitreal aflibercept associated with an increased treatment burden during the first year of therapy. Furthermore, our study verifies previous reports of vasoconstrictive effects of anti-VEGF therapy and extends the results till 12 months follow-up.

While we hypothesized that the pathophysiological association between vessel dilation/hyper-perfusion and disease severity and edema formation would reflect treatment load, our data suggest the opposite (Klein et al. 2004; Kifley et al. 2008; Klein et al. 2012). Thus, our results did not demonstrate any difference in BL vessel calibers between eyes with and without need for PRN treatment after loading with intravitreal aflibercept and macular laser. The only baseline parameter that differed between eyes with and without need for PRN therapy was CRT which was maybe expected even though the difference in CRT was no longer present after loading with aflibercept.

Interestingly, only eyes that needed PRN treatment demonstrated a decrease in retinal arteriolar caliber after loading with aflibercept even though there was no difference in BL arteriolar caliber between eyes with and without need for PRN treatment. This may, however, seem counterintuitive according to the discussion above. We speculate that the VEGF load may be higher in eyes with a greater need for therapy and, hence, the effects of blocking its physiological effects may be more pronounced as compared to in eyes with a smaller burden of treatment. It must, however, be emphasized that no between-group difference was demonstrated.

For the entire cohort, this study demonstrated that both retinal arteriolar and venular calibers decreased during DME-treatment with intravitreal anti-VEGF and furthermore, that the decrease is maintained even after switching from monthly therapy during loading to a PRN regimen. Even eyes that did not receive PRN aflibercept after loading exhibited lasting venular constriction at M12. We assume that the beneficial effect of anti-VEGF therapy on retinal thickness in DME-treatment is at least partly due to reduced hydrostatic pressure as a consequence of a decrease in the pathologically increased vessel calibers towards normal levels. However, it must be emphasized that a similar response to treatment has been reported in neovascular age related macular degeneration (nAMD) even though nAMD is not associated with increased vessel calibers (Micieli et al. 2012; Mendrinos et al. 2013; Tetikoglu et al. 2018).

At M3, a decrease in arteriolar vessel density was demonstrated in eyes that needed PRN treatment. As vessel density is the sum of pixels occupied by retinal vessels in a given retinal area it is expected to fluctuate with vessel calibers. Hence, our results may simply reflect the decrease in retinal arteriolar caliber 
in eyes that needed PRN treatment. However, venular vessel density remained unchanged even though a decrease in venular caliber was demonstrated in both groups. The usage of measuring vessel density is yet not fully understood and is an experimental parameter provided in the VAMPIRE software. We speculate that measuring vessel density may be more useful in predicting development and/or progression of DR than treatment outcome in a similar manner as fractal dimension (Cheung et al. 2009; Broe et al. 2014). Thus, there were no association between BL fractal dimension and treatment outcome in our study despite a well-documented association between fractal dimension and long term risk of vison threatening DR. Neither did the fractal dimension change during treatment in either group.

Our result align with previous reports on the effects of both aflibercept and ranibizumab on retinal vascular calibers in the treatment of DME as well as other retinal vascular diseases (Tatlipinar et al. 2012; Wickremasinghe et al. 2012; Min et al. 2018; Tetikoglu et al. 2018). We speculate that the vasoconstriction of retinal vessels demonstrated in this study following intravitreal injection of aflibercept is probably in truth a mere reversal of the vasodilative effect of VEGF. Thus, animal studies have demonstrated that VEGF induces vasodilation in a dose-dependent fashion to produce transient tachycardia, hypotension and decreased cardiac output (Ferrara 1999). However, studies on retinal vessels in human subject are limited.

Only one study using bevacizumab did not demonstrate any changes in retinal vessel calibers after treatment (Wickremasinghe et al. 2017). Whether this explains any of the difference in functional outcome between aflibercept and ranibizumab over bevacizumab is, however, unknown (Wells et al. 2016).

In addition, our study presents long term outcome on changes in vascular calibers, also in patients that did not receive additional intravitreal therapy after loading. Interestingly, eyes without need for PRN treatment demonstrated lasting venular constriction similar to eyes that continued intravitreal PRN therapy. While retinal images at $\mathrm{BL}$ and $\mathrm{M} 3$ were captured prior to focal/grid laser photocoagulation, images at M12 were captured afterwards. Hence, the measured changes in retinal microvasculature between $B L$ and $M 3$ represent the isolated effect of anti-VEGF, whereas the vessel analyses conducted on images captured at M12 would be affected by both aflibercept and focal/grid laser photocoagulation.

Lundberg et al. demonstrated a narrowing of macular vessels after focal/grid laser photocoagulation. The authors argued that the vessel constriction should be explained by a lowered metabolic demand after destruction of photoreceptors and improved oxygenation by diffusion through laser scars in accordance with the oxygen theory presented by Stefasson (Stefansson 2006). Likewise, vasoconstriction has been readily demonstrated after panretinal photocoagulation and is thought to be explained by the same theory. Thus, it can only be speculated whether the lasting venular constriction demonstrated at M12 can be attributed to adjunctive use of focal/grid laser photocoagulation.

Also, our data does not allow us to test whether eyes without need for PRN treatment demonstrated a more stable decrease in venular calibers during the course of this study as compared to eyes with a continuous need for intravitreal therapy.

Large population-based studies have demonstrated that both retinal arteriolar and venular calibers correlate with age in persons with type 2 diabetes. Thus Klein et al. demonstrated that the caliber of retinal arterioles decrease by approximately $2.0 \mu \mathrm{m} / 10$ years and for retinal venules by approximately $2.5 \mu \mathrm{m} / 10$ years. Given the extend of vascular constriction as well as the relatively short period of follow-up in our 
study, we do, thus, not believe the demonstrated decrease in both retinal arteriolar and venular caliber to be a simple effect of time.

We only measured BMI, HbA1c and blood pressure at BL. Thus we cannot account for whether any these parameters may have changed during the follow-up period and whether potential changes may be different between the groups with and without need for PRN treatment. However, a previous study has demonstrated that glycemic control does not improve even after major events in diabetes as e.g. stroke, blindness or limb amputation (Jorgensen et al. 2009). We may, thus, anticipate that the same will apply in our study even though the lack of repeated measurements is a potential limitation to our study.

Also, no sample size calculation for this specific study was conducted. Instead, sample size was determined for the original randomized controlled trial which may be a limitation to this current study. However, no relevant data could be identified in terms of estimating the expected effect size on retinal microvascular parameters of the intervention described in this study. Consequently, this current study should be considered as explorative.

Despite extensive knowledge about the associations between parameters of retinal microvascular structure and ocular as well as systemic diseases, quantification of retinal microvasculature has currently very limited use in clinical practice. This is largely due to difficulties with translation of results of cross-sectional studies into clinical practice. Hence, the prospective design was a considerable strength of this study as well as the well-characterized study population and pre-specified treatment algorithm. Furthermore, while previous studies have addressed predominantly addressed potential predictors of functional outcome in DME treatment, this study is unique by addressing potential predictors of treatment load which is of great interest from a clinical point of view. Thus, both distinct features of retinal morphology as determined by OCT (disruption of retinal inner layers) as well as retinal oximetry parameters have been suggested as predictors of functional outcome in DME treatment whereas no previous studies have addressed parameters of retinal microvascular structures as predictors of treatment load (Radwan et al. 2015; Sun et al. 2015; Bek \& Jorgensen 2016). This study was, however, limited especially by the number of participants. Furthermore, our study did not include an untreated control group which was, in our case, not possible due to ethical reasons.

In conclusion, our results suggest that early changes in retinal arteriolar caliber are associated with an increased treatment burden during the first year of DME-treatment. Further studies with larger populations are needed to assess fluctuations in retinal vessel calibers between intravitreal injections.

\section{ACKNOWLEDGEMENT}

This study was supported by grants from the University of Southern Denmark, grants from Odense University Hospital, grants from Fight for Sight Denmark, grants from The Synoptik Foundation and grants from The Danish Diabetes Academy supported by the Novo Nordisk Foundation, during the conduct of the study. The funding organizations had no involvement in study design, data collection, data analysis, manuscript preparation and/or publication decision.

We thank all funding organizations for the financial support received for this study and the Department of Ophthalmology, Odense University Hospital for providing the facilities and equipment necessary. 
Aiello LP, RL Avery, PG Arrigg, BA Keyt, HD Jampel, ST Shah, LR Pasquale, H Thieme, MA Iwamoto, JE Park \& et al. (1994): Vascular endothelial growth factor in ocular fluid of patients with diabetic retinopathy and other retinal disorders. N Engl J Med 331: 1480-1487.

Antonetti DA, R Klein \& TW Gardner (2012): Diabetic retinopathy. N Engl J Med 366: 1227-1239.

Bek T \& CM Jorgensen (2016): The Systemic Blood Pressure and Oxygen Saturation in Retinal Arterioles Predict the Effect of Intravitreal Anti-VEGF Treatment on Diabetic Maculopathy. Invest Ophthalmol Vis Sci 57: 5429-5434.

Blindbaek SL, T Peto \& J Grauslund (2019): Aflibercept and navigated versus conventional laser in diabetic macular edema: a 12-month prospective, randomized clinical trial. The Association for research in Vision and Ophthalmology (ARVO), annual meeting 2019. Vancouver, B.C. Session: Diabetic Macular Edema Clinical Research, abstract number: 2627 - B0158.

Broe R, ML Rasmussen, U Frydkjaer-Olsen, BS Olsen, HB Mortensen, T Peto \& J Grauslund (2014): Retinal vascular fractals predict long-term microvascular complications in type 1 diabetes mellitus: the Danish Cohort of Pediatric Diabetes 1987 (DCPD1987). Diabetologia 57: 2215-2221.

Cheung N, KC Donaghue, G Liew, SL Rogers, JJ Wang, SW Lim, AJ Jenkins, W Hsu, M Li Lee \& TY Wong (2009): Quantitative assessment of early diabetic retinopathy using fractal analysis. Diabetes Care 32: 106-110.

Cheung N, P Mitchell \& TY Wong (2010): Diabetic retinopathy. Lancet 376: 124-136.

Cho NH, K J., MJ C., K Ogurstova, L Guariguata, W Rathmann, G Roglic, N Forouhi, R Dajani, A Esteghamati, E Boyko, I Hambleton, OLdM Neto, PA Montoya, S Joshi, J Chan, J Shaw, TA Samuels, M Pavkov \& A Reja (2017): International Diabetes Federation Diabetes Atlas, 8th Edition.

Cogan DG \& T Kuwabara (1963): CAPILLARY SHUNTS IN THE PATHOGENESIS OF DIABETIC RETINOPATHY. Diabetes 12: 293-300.

Consigli A, A Papanastasiou, D Roquelaure, R Wuarin, S Roy, G Thumann \& A Chronopoulos (2018): [Changes in Retinal Vascular Caliber after Intravitreal Aflibercept Treatment for Diabetic Macular Oedema]. Klin Monbl Augenheilkd.

Ferrara N (1999): Molecular and biological properties of vascular endothelial growth factor. Journal of molecular medicine (Berlin, Germany) 77: 527-543.

Grauslund J, A Green \& AK Sjolie (2009): Prevalence and 25 year incidence of proliferative retinopathy among Danish type 1 diabetic patients. Diabetologia 52: 1829-1835.

Jorgensen TM, J Grauslund, AK Sjolie, A Green, LM Rasmussen \& M Nybo (2009): Major diabetes-related vascular events do not improve glycaemic control in a population-based cohort of type 1 diabetic individuals. Scand J Clin Lab Invest 69: 748-751.

Kifley A, JJ Wang, S Cugati, TY Wong \& P Mitchell (2008): Retinal vascular caliber and the long-term risk of diabetes and impaired fasting glucose: the Blue Mountains Eye Study. Microcirculation (New York, N.Y. : 1994) 15: 373-377.

Klein R, BE Klein, SE Moss, TY Wong, L Hubbard, KJ Cruickshanks \& M Palta (2004): The relation of retinal vessel caliber to the incidence and progression of diabetic retinopathy: XIX: the Wisconsin Epidemiologic Study of Diabetic Retinopathy. Archives of ophthalmology 122: 76-83.

Klein R, KE Lee, RE Gangnon \& BE Klein (2010): The 25-year incidence of visual impairment in type 1 diabetes mellitus the wisconsin epidemiologic study of diabetic retinopathy. Ophthalmology 117: 63-70.

Klein R, CE Myers, KE Lee, R Gangnon \& BE Klein (2012): Changes in retinal vessel diameter and incidence and progression of diabetic retinopathy. Archives of ophthalmology 130: 749-755.

Knudtson MD, KE Lee, LD Hubbard, TY Wong, R Klein \& BE Klein (2003): Revised formulas for summarizing retinal vessel diameters. Current eye research 27: 143-149.

Lundberg K, R Kawasaki, AK Sjølie, TY Wong \& J Grauslund (2013): Localized changes in retinal vessel caliber after focal/grid laser treatment in patients with diabetic macular edema: A measure of treatment response? Retina (Philadelphia, Pa.) 33: 2089-2095. 
McGrory S, AM Taylor, E Pellegrini, L Ballerini, M Kirin, FN Doubal, JM Wardlaw, ASF Doney, B Dhillon, JM Starr, E Trucco, IJ Deary \& TJ MacGillivray (2018): Towards Standardization of Quantitative Retinal Vascular Parameters: Comparison of SIVA and VAMPIRE Measurements in the Lothian Birth Cohort 1936. Transl Vis Sci Technol 7: 12.

Mendrinos E, G Mangioris, DN Papadopoulou, G Donati \& CJ Pournaras (2013): Long-term results of the effect of intravitreal ranibizumab on the retinal arteriolar diameter in patients with neovascular age-related macular degeneration. Acta Ophthalmol 91: e184-190.

Micieli JA, E Tsui, WC Lam, MH Brent, RG Devenyi \& C Hudson (2012): Retinal blood flow in response to an intravitreal injection of ranibizumab for neovascular age-related macular degeneration. Acta Ophthalmol 90: e13-20.

Min JK, S Lee, JH Park, JM Woo \& HS Yang (2018): Effects of intravitreal aflibercept and ranibizumab on retinal vessel diameter measured using fluorescein angiography. Acta Ophthalmol 96: e546-e547.

Moradi A, YJ Sepah, MA Ibrahim, R Sophie, C Moazez, MG Bittencourt, RE Annam, M Hanout, H Liu, D Ferraz, DV Do \& QD Nguyen (2014): Association of retinal vessel calibre and visual outcome in eyes with diabetic macular oedema treated with ranibizumab. Eye (Lond) 28: 1315-1320.

Perez-Rovira A, T MacGillivray, E Trucco, KS Chin, K Zutis, C Lupascu, D Tegolo, A Giachetti, PJ Wilson, A Doney \& B Dhillon (2011): VAMPIRE: Vessel assessment and measurement platform for images of the REtina. Conf Proc IEEE Eng Med Biol Soc 2011: 3391-3394.

Radwan SH, AZ Soliman, J Tokarev, L Zhang, FJ van Kuijk \& DD Koozekanani (2015): Association of Disorganization of Retinal Inner Layers With Vision After Resolution of Center-Involved Diabetic Macular Edema. JAMA Ophthalmol 133: 820-825.

Senger DR, CA Perruzzi, J Feder \& HF Dvorak (1986): A highly conserved vascular permeability factor secreted by a variety of human and rodent tumor cell lines. Cancer Res 46: 5629-5632.

Stefansson E (2006): Ocular oxygenation and the treatment of diabetic retinopathy. Surv Ophthalmol 51: 364-380.

Stitt AW, TM Curtis, M Chen, RJ Medina, GJ McKay, A Jenkins, TA Gardiner, TJ Lyons, HP Hammes, R Simo \& $\mathrm{N}$ Lois (2016): The progress in understanding and treatment of diabetic retinopathy. Prog Retin Eye Res 51: 156-186.

Sun JK, SH Radwan, AZ Soliman, J Lammer, MM Lin, SG Prager, PS Silva, LB Aiello \& LP Aiello (2015): Neural Retinal Disorganization as a Robust Marker of Visual Acuity in Current and Resolved Diabetic Macular Edema. Diabetes 64: 2560-2570.

Tan GS, N Cheung, R Simo, GC Cheung \& TY Wong (2017): Diabetic macular oedema. Lancet Diabetes Endocrinol 5: 143-155.

Tatlipinar S, UA Dinc, NM Yenerel \& E Gorgun (2012): Short-term effects of a single intravitreal bevacizumab injection on retinal vessel calibre. Clin Exp Optom 95: 94-98.

Tetikoglu M, MM Kurt, HM Sagdik, S Aktas, MA Yildirim \& F Ozcura (2018): Retrospective analysis of the effect of aflibercept loading dose on the retinal vessel diameters in patients with treatment-naive neovascular AMD(). Cutan Ocul Toxicol 37: 84-89.

Wells JA, AR Glassman, AR Ayala, LM Jampol, NM Bressler, SB Bressler, AJ Brucker, FL Ferris, GR Hampton, C Jhaveri, M Melia \& RW Beck (2016): Aflibercept, Bevacizumab, or Ranibizumab for Diabetic Macular Edema: Two-Year Results from a Comparative Effectiveness Randomized Clinical Trial. Ophthalmology.

Wickremasinghe SS, S Fraser-Bell, E Alessandrello, H Mehta, MC Gillies \& LL Lim (2017): Retinal vascular calibre changes after intravitreal bevacizumab or dexamethasone implant treatment for diabetic macular oedema. Br J Ophthalmol 101: 1329-1333.

Wickremasinghe SS, J Xie, RH Guymer, TY Wong, R Kawasaki \& S Qureshi (2012): Retinal vascular changes following intravitreal ranibizumab injections for neovascular AMD over a 1-year period. Eye (Lond) 26: 958-966. 
Fig. 1

460 Illustration of vessel analysis using VAMPIRE web (Vessel Assessment and Measurement Platform for 461 Images of the Retina, Universities of Dundee and Edinburgh, UK). Vessel calibers are measured zone B (0.54621.0 disc diameters from the optic disc margin) and tortuosity, vessel density and fractal dimension in zone $C$ 463 (0.5-2.0 disc diameters from the optic disc margin). Arterioles and venules are labelled in red and blue, 464 respectively, and segments excluded from analysis are labelled in white.

465 
Table 1 Baseline characteristics of eyes with and without need for intravitreal aflibercept after laser

\begin{tabular}{|c|c|c|c|c|}
\hline & Total $(n=32)$ & $P R N \div(n=15)$ & $P R N+(n=17)$ & $p$ \\
\hline \multicolumn{5}{|l|}{ Demographics } \\
\hline Age (years) & $59.5(57.7-64.3)$ & $61.6(55.7-67.5)$ & $57.7(51.6-63.9)$ & 0.28 \\
\hline Sex (\% women) & 21.9 & 13.3 & 29.4 & 0.40 \\
\hline $\begin{array}{l}\text { Duration of diabetes } \\
\text { (years) }\end{array}$ & $9.2(4.6-13.7)$ & $9.9(2.7-17.0)$ & $8.5(3.3-13.7)$ & 0.74 \\
\hline $\begin{array}{l}\text { Hemoglobin A1c } \\
(\mathrm{mmol} / \mathrm{mol})\end{array}$ & $59.8(52.2-67.4)$ & $60.9(47.7-74.2)$ & $58.9(51.8-65.9)$ & 0.76 \\
\hline Body mass index $\left(\mathrm{kg} / \mathrm{m}^{2}\right)$ & $29.2(26.5-32.0)$ & $29.6(26.9-32.4)$ & $28.9(24.7-33.1)$ & 0.74 \\
\hline $\mathrm{MAP}(\mathrm{mmHg})$ & $101.9(96.0-107.8)$ & $101.5(95.3-107.8)$ & $102.2(92.8-111.6)$ & 0.90 \\
\hline BCVA (ETDRS letters) & $71.7(68.2-75.3)$ & $73.3(70.2-76.4)$ & $70.4(63.7-77.0)$ & 0.44 \\
\hline CRT $(\mu \mathrm{m})$ & $387.3(352.0-422.6)$ & $344.6(325.5-363.7)$ & $424.9(360.6-489.2)$ & $0.03 *$ \\
\hline \multicolumn{5}{|l|}{ Microvascular parameters } \\
\hline \multicolumn{5}{|l|}{ Caliber $(\mu \mathrm{m})$} \\
\hline Arterioles & $139.9(133.3-146.5)$ & $141.6(131.5-151.7)$ & $138.4(129.6-147.1)$ & 0.62 \\
\hline Venules & $212.8(206.1-219.4)$ & $208.2(202.8-213.7)$ & $216.8(205.4-228.3)$ & 0.17 \\
\hline \multicolumn{5}{|l|}{ Toruosity } \\
\hline Arterioles & $-8.2(-8.8-(-7.7))$ & $-8.0(-9.2-(-6.8))$ & $-8.4(-8.7-(-8.2))$ & 0.48 \\
\hline Venules & $-8.4(-8.5-(-8.2))$ & $-8.4(-8.6-(-8.2))$ & $-8.3(-8.6-(-8.1))$ & 0.58 \\
\hline \multicolumn{5}{|l|}{ Vessel density (pixels) } \\
\hline Arterioles & 3961.5 (3514.2-4408.8) & 3953.9 (3426.5-4481.3) & $3968.2(3248.9-4687.6)$ & 0.97 \\
\hline Venules & $5532.1(5108.2-5956.0)$ & 5410.8 (4799.7-6021.9) & 5639.1 (5069.6-6208.6) & 0.58 \\
\hline \multicolumn{5}{|l|}{ Fractal dimension } \\
\hline Arterioles+venules & $1.374(1.361-1.388)$ & 1.369 (1.346-1.391) & 1.379 (1.363-1.396) & 0.46 \\
\hline
\end{tabular}

*Indicates $p$-value $<0.05$ and calculated for the comparison between groups of treatment success and treatment failure. PRN $\div$ : eyes without need for additional intravitreal therapy (pro re nata) after loading, PRN+: eyes with need for additional intravitreal therapy (pro re nata) after loading, MAP: mean arterial blood pressure, BCVA: best corrected visual acuity, CRT: central retinal thickness. 
Table 2 Changes in retinal microvasculature at three and twelve months follow-up in patients with, respectively, success and failure of DME-treatment with 3 monthly injections of $2.0 \mathrm{mg}$ aflibercept and focal/grid laser photocoagulation.

\begin{tabular}{|c|c|c|c|c|c|c|c|}
\hline & & \multicolumn{3}{|c|}{ BL-M3 } & \multicolumn{3}{|c|}{ BL-M12 } \\
\hline \multicolumn{2}{|c|}{ Microvascular parameters } & $\mathrm{n}$ & $\Delta$-value & $p_{B}$ & $\mathrm{n}$ & $\Delta$-value & $p_{B}$ \\
\hline \multicolumn{8}{|l|}{ Caliber ( $\mu \mathrm{m})$} \\
\hline \multirow[t]{3}{*}{ Arterioles } & $P R N \div$ & 15 & $-1.6(-13.8-10.7)$ & 0.79 & 15 & $-7.0(-18.6-4.5)$ & 0.22 \\
\hline & $\mathrm{PRN}+$ & 15 & $-11.2(-18.7-(-3.7))$ & $0.005^{*}$ & 17 & $-11.5(-22.2-(-0.8))$ & $0.04^{*}$ \\
\hline & $p_{\alpha}$ & & 0.17 & & & 0.55 & \\
\hline \multirow[t]{3}{*}{ Venules } & $\mathrm{PRN} \div$ & 15 & $-11.6(-20.1-(-3.1))$ & $0.01 *$ & 15 & $-11.0(-22.1-(-0.19))$ & $0.04 *$ \\
\hline & $\mathrm{PRN+}$ & 15 & $-9.5(-17.0-(-2.0))$ & $0.01^{*}$ & 17 & $-15.6(-24.0-(-7.2))$ & $0.001 *$ \\
\hline & $p_{\alpha}$ & & 0.70 & & & 0.50 & \\
\hline \multicolumn{8}{|l|}{ Tortuosity } \\
\hline \multirow[t]{3}{*}{ Arterioles } & PRN $\div$ & 15 & $1.5(-0.3-3.2)$ & 0.10 & 15 & $0.2(-1.7-2.0)$ & 0.86 \\
\hline & PRN+ & 15 & $1.6(-0.1-3.3)$ & 0.07 & 17 & $1.9(-0.2-4.1)$ & 0.07 \\
\hline & $p_{\alpha}$ & & 0.90 & & & 0.18 & \\
\hline \multirow[t]{3}{*}{ Venules } & PRN $\div$ & 15 & $-0.2(-0.4-0.1)$ & 0.14 & 15 & $0.5(-0.8-1.7)$ & 0.45 \\
\hline & $\mathrm{PRN}+$ & 15 & $-0.2(-0.4-0.0)$ & 0.11 & 17 & $0.3(-0.8-1.3)$ & 0.57 \\
\hline & $p_{\alpha}$ & & 0.95 & & & 0.83 & \\
\hline \multicolumn{8}{|l|}{ Vessel density (pixels) } \\
\hline \multirow[t]{3}{*}{ Arterioles } & $\mathrm{PRN} \div$ & 15 & $-382.9(-828.9-61.2)$ & 0.09 & 15 & $17.3(-572.9-607.4)$ & 0.95 \\
\hline & PRN+ & 15 & $-367.3(-720.7-(-13.9)$ & $0.04 *$ & 17 & $-200.6(-710.8-309.6)$ & 0.42 \\
\hline & $p_{\alpha}$ & & 0.95 & & & 0.57 & \\
\hline \multirow[t]{3}{*}{ Venules } & $\mathrm{PRN} \div$ & 15 & $-334.5(-809.7-140.7)$ & 0.16 & 15 & $-170.6(-745.6-404.4)$ & 0.55 \\
\hline & $\mathrm{PRN}+$ & 15 & $-142.0(-493.7-209.7)$ & 0.41 & 17 & $-202.8(-546.6-141.1)$ & 0.24 \\
\hline & $p_{\alpha}$ & & 0.49 & & & 0.92 & \\
\hline \multicolumn{8}{|l|}{ Fractal Dimension } \\
\hline \multirow[t]{3}{*}{ Arterioles+venules } & PRN $\div$ & 15 & $0.001(-0.023-0.025)$ & 0.91 & 15 & $0.010(-0.010-0.034)$ & 0.31 \\
\hline & $\mathrm{PRN}+$ & 15 & $0.001(-0.014-0.016)$ & 0.85 & 17 & $-0.001(-0.017-0.016)$ & 0.92 \\
\hline & $p_{\alpha}$ & & $>0.99$ & & & 0.37 & \\
\hline
\end{tabular}

*Indicates $p$-value $<0.05$.

$P R N \div$ : eyes without need for additional intravitreal therapy (pro re nata) after loading, PRN+: eyes with need for additional intravitreal therapy (pro re nata) after loading. BL: baseline, M3: month 3, M12: month 12, $\Delta$ : change from baseline to specified time for follow-up, $p_{\alpha}$ : difference between groups of treatment success and treatment failure, $p_{B}$ : difference between $B L$ and follow-up at $\mathrm{M} 3$ and $\mathrm{M} 12$, respectively. 


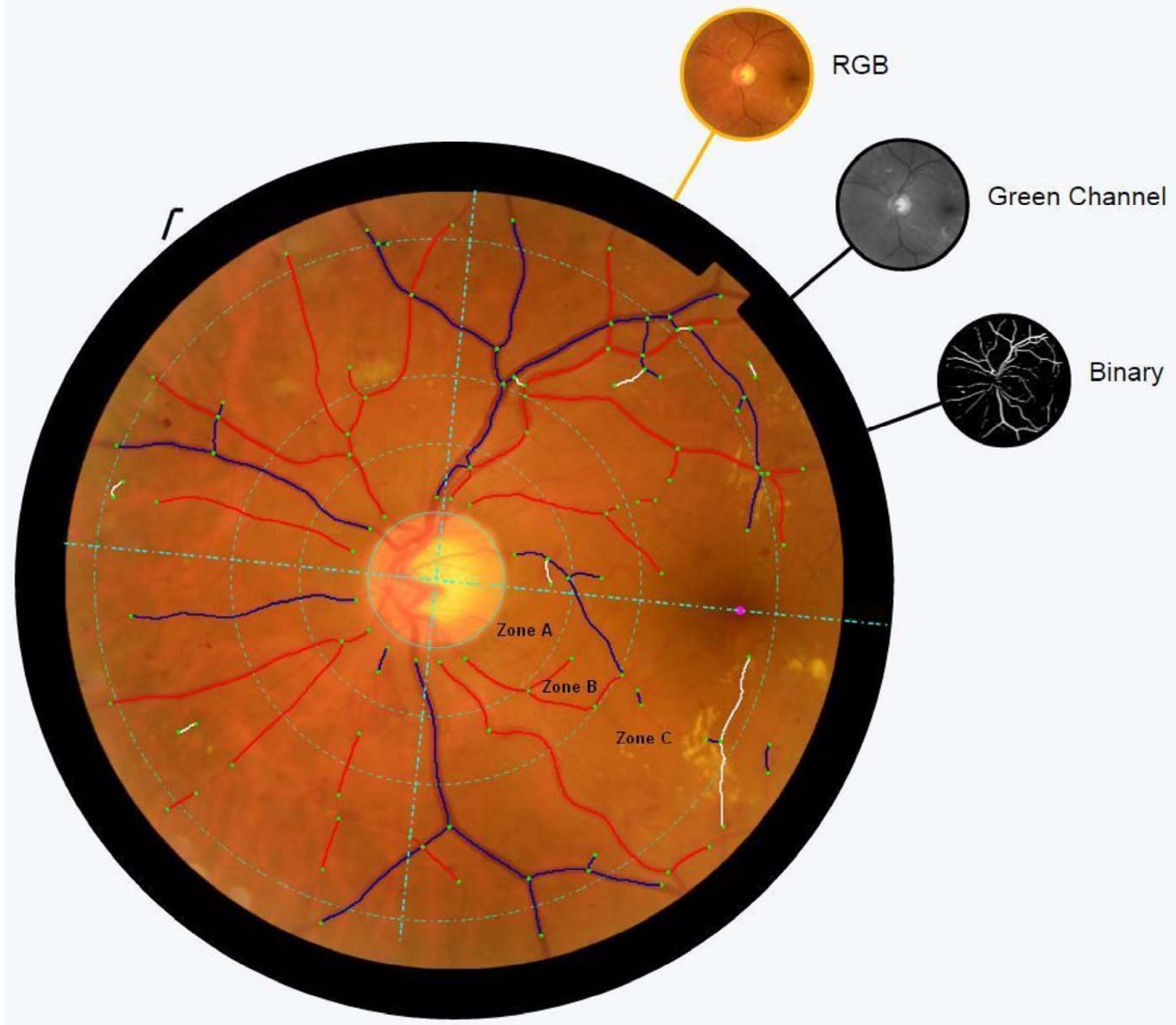

